\title{
Free and sulfated steroids secretion in postpubertal boars (Sus scrofa domestica)
}

\author{
G Schuler ${ }^{1}$, Y Dezhkam¹, L Bingsohn, B Hoffmann ${ }^{1}$, K Failing ${ }^{2}$, C E Galuska ${ }^{3}$, M F Hartmann³, \\ A Sánchez-Guijo ${ }^{3}$ and S A Wudy ${ }^{3}$ \\ ${ }^{1}$ Veterinary Clinic for Obstetrics, Gynecology and Andrology of Large and Small Animals, Faculty of Veterinary \\ Medicine, ${ }^{2}$ Unit of Biomathematics and Data Processing and ${ }^{3}$ Steroid Research and Mass Spectrometry Unit, Center \\ of Child and Adolescent Medicine, Justus-Liebig-University, Frankfurter Strasse 106, D-35392 Giessen, Germany
}

Correspondence should be addressed to G Schuler; Email: gerhard.schuler@vetmed.uni-giessen.de

\begin{abstract}
Sulfated steroids have been traditionally regarded as inactive metabolites. However, they may also serve as precursors for the production of active free steroids in target cells. In this study, we used the boar as a model to study the metabolism, transport, and function of steroid sulfates due to their high production in the porcine testicular-epididymal compartment, of which the role is unknown. To characterize the secretion of free and sulfated steroids, plasma samples were collected from six postpubertal boars over $6 \mathrm{~h}$ every $20 \mathrm{~min}$ from the jugular vein. Long-term secretion profiles were also established in seven boars stimulated with human chorionic gonadotropin. To directly characterize the testicular output, samples were collected from superficial testicular arterial and venous blood vessels. Testosterone, androstenedione and sulfated pregnenolone, DHEA, estrone $\left(E_{1}\right)$, and estradiol-17 $\beta$ ( $\left.E_{2}\right)$ were determined by liquid chromatography-tandem mass spectrometry. Free $E_{1}$ and $E_{2}$ were measured by RIA. Irrespective of a high variability between individuals, the results suggest that i) all steroids assessed are primarily produced in the testis, ii) they exhibit similar profiles pointing to a pulsatile secretion with low frequency (three to five pulses per day), and iii) after synthesis at least a major proportion is immediately released into peripheral circulation. The fact that all steroid sulfates assessed are original testicular products and their high correlations with one another suggest their role as being intermediates of testicular steroidogenesis rather than as being inactivated end products. Moreover, a substantial use of sulfated steroids in porcine testicular steroidogenesis would assign a crucial regulatory role to steroid sulfatase, which is highly expressed in Leydig cells.

Reproduction (2014) 148 303-314
\end{abstract}

\section{Introduction}

In boars, testicular steroid synthesis is characterized by the production of high amounts of sulfated steroids, including estrone sulfate $\left(E_{1} S\right)$ and DHEA sulfate (DHEAS) (Baulieu et al. 1967, Claus \& Hoffmann 1980, Tan \& Raeside 1980, Schwarzenberger et al. 1993, Zamaratskaia et al. 2004, Hoffmann et al. 2010), of which the synthetic pathways, transport, and the biological role are still unclear. Sulfation of steroids abolishes their capability to bind to and thus to activate classical nuclear steroid receptors (Hähnel et al. 1973, Kuiper et al. 1997), and it dramatically increases their polarity, thus reducing their distribution volume. Moreover, due to an enhanced protein binding, the half-life of sulfated steroids is longer and they may circulate in substantially higher concentrations compared with their free counterparts (Back et al. 1981, Strott 1996, Raftogianis et al. 2000). So far, sulfation of steroids has been commonly considered as an important mechanism leading to their inactivation and excretion. On the other hand, sulfated steroids may form a pool of precursors, from which, after hydrolysis catalyzed by the enzyme steroid sulfatase, active free steroids may be formed locally in target tissues. This sulfatase pathway has been identified as the major route of local estrogen production in human hormone-dependent breast cancer tissues (Santner et al. 1984, Reed et al. 2005). Interestingly, in the porcine testicular-epididymal compartment not only the production of high amounts of sulfated steroids was observed but also a considerable expression of steroid sulfatase (Mutembei et al. 2009, Hoffmann et al. 2010, Zdunczyk et al. 2012).

In contrast to free steroids, commonly considered to freely distribute in tissues by passive diffusion (Mendel 1989, Willnow \& Nykjaer 2010), the transport of the substantially more polar sulfated steroids across the membrane obviously depends on more- or less-specific transport mechanisms. Thus, the cellular import or 
export of sulfated steroids may provide mechanisms for their directed transport within and between tissues. Several steroid sulfate transporter candidates have been suggested (Geyer et al. 2004, Bortfeld et al. 2006, Ugele et al. 2008); however, their actual role in the cellular uptake or export of sulfated steroids under in vivo conditions is still mostly unclear.

Inactivation of steroid hormones by sulfation may occur in target cells (Meyers et al. 1983) and in the liver (Duanmu et al. 2006). In boars, however, comparative measurements in arterial and venous blood and in lymph of the spermatic cord clearly show that the high levels of sulfated steroids are not primarily resulting from peripheral metabolism, but are unequivocally produced in significant amounts in the testicular-epididymal compartment (Baulieu et al. 1967, Setchell et al. 1983, Hoffmann et al. 2010). Up to date, the underlying pathways for the synthesis of sulfated estrogens and other sulfated steroids in the boar testis are still unclear. Despite some evidence that the tubular compartment may contribute to testicular estrogen production (Rago et al. 2007, At-Taras et al. 2008), by means of immunohistochemistry the detection of aromatase was consistently confined to Leydig cells, clearly evidence that from a quantitative point of view they are the only significant source of free estrogens in the postpubertal porcine testis (Conley et al. 1996, Fraczek et al. 2001, Mutembei et al. 2005, Weng et al. 2005). Concerning their sulfation, however, no activity of estrogen sulfotransferase was detectable in testicular tissue, whereas significant activity was found in the epididymis (Hoffmann et al. 2010, Zdunczyk et al. 2012). This may suggest that free estrogens produced in the testis may be sulfated to a substantial extent in the epididymis. To date, there is no experimental confirmation of this concept and also the mechanisms accomplishing this hypothetical transfer of free estrogens from the testis to the epididymis while preventing their significant leakage into the systemic circulation are fully unclear.

The aim of our ongoing studies is to get further 'in vivo' insights into the formation, transport, and function of sulfated steroids within the testicular-epididymal compartment in boars to extend our knowledge of the specific reproductive endocrinology of this species and to obtain basic information with respect to the suitability of the boar as a model for the study of the sulfatase pathway. In this paper, we address the secretion patterns of androstenedione $\left(A_{4}\right)$, testosterone, estradiol- $17 \beta\left(E_{2}\right)$, estrone $\left(E_{1}\right)$, estradiol-17 $\beta$-3-sulfate $\left(E_{2} S\right), E_{1} S$, pregnenolone sulfate (PREGS), and DHEAS, which are considered to be key steroids with respect to the hypothesized sulfatase pathway. It was further hypothesized that qualitative differences in the secretion pattern, such as phase shiftings or different degrees of decoupling, might occur when the synthesis of free steroids and their sulfation are differently regulated in different organs (testis vs epididymis) or in the case of differential transport (blood, lymph, and rete testis fluid). As these effects might become particularly obvious in the case of significant fluctuations of production rates, thus, in addition to long-term measurements in unstimulated animals, human chorionic gonadotropin (hCG) application was used to induce a more dynamic situation. Although a significant amount of data on steroid levels is available in boars (for review see Raeside et al. (2006)), including profiles after hCG stimulation, a holistic view from long-term measurements of free and sulfated steroids with high frequent sampling including a significant number of animals is still missing. Moreover, in order to characterize more precisely the immediate testicular output of free and sulfated steroids, comparative measurements in arterial and venous blood vessels penetrating the testicular capsule were performed.

\section{Materials and methods}

\section{Sample collection from unstimulated boars}

All animal experiments were in accordance with the relevant regulations and were approved by the competent authority (Regierungspräsidium Giessen, permit no. V54-19c-20-15(I) Gi 18/14-no. 32/2010). Blood samples from six unstimulated boars (UB1-6, German Landrace $\times$ Pietrain) aged 8-11 months (mean, $9.1 \pm 1.2$ months) were collected from the jugular vein via an indwelling catheter inserted into the ear vein, basically following the procedure as described by Niiyama et al. (1985). For insertion of the catheter, the animals were deeply sedated by receiving an i.m. injection of $2 \mathrm{mg}$ azaperone $/ \mathrm{kg}$ body weight (Stresnil - Janssen Animal Health, Neuss, Germany) and $20 \mathrm{mg}$ ketamine/kg body weight (Ursotamin $100 \mathrm{mg} / \mathrm{kg}$, Serumwerk Bernburg AG, Bernburg, Germany). Insertion of the catheter was made from the middle or lateral auricular vein by using a trocar-cannula type needle (Cavafix Certo, $45 \mathrm{~cm} / 16$ and Certo Splittocan, $5 \mathrm{~cm} / 14 \mathrm{G}$ - B.Braun Melsungen AG, Melsungen, Germany). The free end of the catheter was connected to a feeding tube (Rüsch No. 5, WdT e.G., Garbsen, Germany) used as an extension, which was stitched down at several sites of the ear, neck, and back. Immediately after application of the catheter, the collection of blood samples was started, which was between 0900 and 0945 h. A total of 20 samples were taken at 20 min intervals. The blood was drawn into heparinized $9 \mathrm{ml}$ collection syringes (Monovette Sarstedt, Nümbrecht, Germany), immediately centrifuged, and the resulting plasma stored on ice until freezing at $-20{ }^{\circ} \mathrm{C}$. After collecting the blood sample, the catheter and its extension were filled with heparinized saline $(20 \mathrm{IU} / \mathrm{ml})$, which was thoroughly removed immediately before the collection of the next sample. The animals were somnolent at the beginning of the sampling procedure, started to wake up gradually after about $1 \mathrm{~h}$, and were fully conscious after about another hour. Before the experiments, the boars were kept in spacious boxes alone or together with another boar. For sample collection, they either remained in the box, or - in case there was a second boar in the box - the animals were placed in a mobile cage, which was moved to an adjacent stimulus-poor room within the same building. 


\section{Sample collection from hCG-stimulated boars}

Sample collection was carried out as described earlier for unstimulated boars. In a first trial using three 9-month-old boars (SB1-3, German Landrace XPietrain), two prestimulatory samples were taken 20 min apart, followed by an i.v. injection of $1500 \mathrm{IU}$ hCG (Ovogest - Intervet, Unterschleissheim, Germany). After hCG application, blood sample collection was continued at $20 \mathrm{~min}$ intervals for another $6 \mathrm{~h}$ (protocol 1). In order to define the prestimulatory steroid levels more accurately and to assess more precisely the hormonal changes immediately after hCG stimulation, in a second trial with four German Landrace $\times$ Pietrain crossbred boars (SB4-7) aged between 11 and 15 months (mean, 12.2 \pm 1.4 months), four prestimulatory samples were taken at $20 \mathrm{~min}$ intervals. The sampling interval was then reduced to 10 min during the first hour after application of 1500 IU hCG and thereafter, another 16 samples were collected at 20 min intervals (protocol 2). Finally, in a pilot experiment using an 11.5 months old large white boar (SB8), the hCG dosage was increased to $10000 \mathrm{IU}$ to exert maximum stimulation, and the poststimulatory sampling intervals were further reduced to increase the resolution of the hormonal profiles (protocol 3). Sampling was carried out at $5 \mathrm{~min}$ intervals from $15 \mathrm{~min}$ before to $15 \mathrm{~min}$ after hCG stimulation, followed by sampling at 3 min intervals during the following hour. A last sample was taken 90 min after hCG stimulation.

\section{Sample collection from local blood vessels of the testis and spermatic cord}

The blood samples were collected from local blood vessels of the testis and the spermatic cord from four 11-19 (mean, $14.4 \pm 2.9$ ) month old boars (two German Landrace $\times$ Pietrain crossbreds and two Large Whites). The animals were anaesthetized as described earlier with increased dosages of ketamine in case of insufficient analgesia. The testis and spermatic cord were exposed through a median prescrotal incision and blood samples were collected i) from up to three small veins running in the testicular capsule near the proximal pole of the testis (capsular vein), ii) from the terminal part of the testicular artery running on the testicular surface near the distal pole (capsular artery), and iii) from a vein of the proximal part of the pampiniform plexus, hereafter referred to as the testicular vein. Moreover, a blood sample was obtained from the testicular artery proximal to the pampiniform plexus either by puncture or by collection from arterial bleeding after transection of the spermatic cord (Fig. 1). After completion of blood sampling and removal of the testis with epididymis and the distal part of the spermatic cord, which was performed for a concomitantly ongoing study on the expression of steroidogenic enzymes, the animals were killed following standard veterinary procedures.

\section{Measurement of free and sulfated steroids by liquid chromatography-tandem mass spectrometry}

$\mathrm{A}_{4}$, testosterone, PREGS, DHEAS, $\mathrm{E}_{1} \mathrm{~S}$, and $\mathrm{E}_{2} \mathrm{~S}$, were quantified in boar heparin plasma using isotope dilution liquid

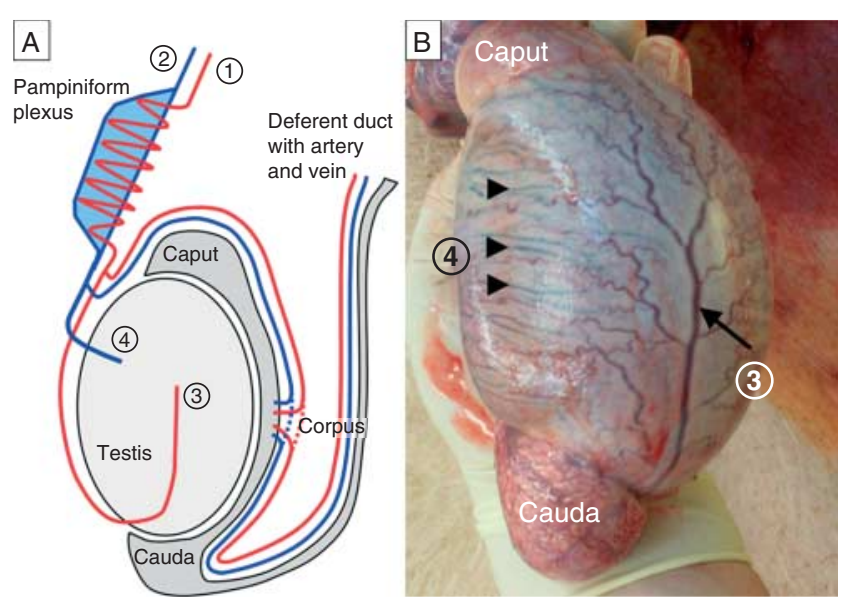

Figure 1 Localizations of sampling from local blood vessels. (A) Schematic presentation of major blood vessels of the testicularepididymal compartment (adopted and modified from Einer-Jensen \& Hunter (2005)) and localizations of blood sampling. (B) Photo of a porcine testis showing the distal part of the testicular artery ('capsular artery', arrow) with its terminal branches and small veins emanating from the testicular tissue ('capsular veins', arrowheads). Up to three venous samples were collected from the individual animals.

(1) Testicular artery before the passage of the pampiniform plexus;

(2) testicular vein; (3) terminal part of the testicular artery; and

(4) capsular veins.

chromatography-tandem mass spectrometry (LC-MS/MS), as previously published (Galuska et al. 2013). Briefly, the samples were mixed and equilibrated with deuterated internal standards $\left(\mathrm{d}_{4} \mathrm{E} 2 \mathrm{~S}, \mathrm{~d}_{4}\right.$ PREGS, $\mathrm{d}_{3} \mathrm{~T}, \mathrm{~d}_{7}-4 \mathrm{~A}$, and $\mathrm{d}_{6}$ DHEAS). All the internal standards except $d_{6}$ DHEAS were purchased from C/D/N Isotopes, Inc. (Point-Claire, QC, Canada). Unlabeled standards and $d_{6}$ DHEAS were obtained from Sigma-Aldrich Chemie GmbH (Taufkirchen, Germany).

After protein precipitation and removal, the samples were evaporated, redissolved in water, and extracted using SepPak C18 cartridges (Waters Corporation, Milford, MA, USA). The methanolic eluates were split into two identical volumes, evaporated, and reconstituted in different solutions for free steroids or sulfated steroids. The steroids were chromatographically separated with a C18 reverse-phase column (Thermo Fisher Scientific, Dreieich, Germany) adapted to a HPLC system (1200 SL systems, Agilent, Waldbronn, Germany).

The sulfated steroids ( $E_{1} S, E_{2} S$, DHEAS, and PREGS) were ionized in a negative mode using electrospray ionization, whereas free steroids (testosterone and $\mathrm{A}_{4}$ ) were ionized in a positive mode by atmospheric pressure chemical ionization. Detection and quantification were performed with a triple quadrupole mass spectrometer (TSQ Quantum Ultra, Thermo Fisher Scientific) in tandem mass configuration.

The LC-MS/MS-based method for the measurement of $A_{4}$ was established immediately after the start of the analytical work. Thus, no data on $\mathrm{A}_{4}$ concentrations are available for one unstimulated (UB1) and one stimulated boar (SB1). As the LCMS/MS-based method for the measurement of $E_{2} S$ only became available during the final stage of this study, it was solely applied to the samples collected from two hCG-stimulated boars and to samples collected from peripheral blood and local 
blood vessels of four boars during tissue sampling. Thus, the data from these determinations are presented separately.

\section{Measurement of $E_{1}, E_{2}$, and cortisol by RIA}

To cope with the relatively low concentrations of free $E_{2}$ and $E_{1}$ in boars, sensitive inhouse RIAs were used for measurements.

The samples in which $\mathrm{E}_{2} \mathrm{~S}$ was determined, concentrations of free $E_{2}$ were also measured as previously described. Cross-reactions of the antiserum used were $1.3 \%$ for $E_{1}$ and $<0.01 \%$ for $\mathrm{A}_{4}, \mathrm{DHEA}, \mathrm{PREG}$, progesterone $\left(\mathrm{P}_{4}\right)$, and testosterone (Hoffmann et al. 1992). $\mathrm{E}_{1}$ was measured in all samples using a sequential assay (Strecker et al. 1979), basically following the method described for the measurement of $E_{2}$. The antiserum used was obtained from a rabbit immunized with estrone-6-carboxymethyloxim coupled to BSA (cross-reactions: $E_{2}, 2.3 \%$; estradiol-17 $\alpha, 0.7 \%$; DHEA, $0.2 \%$; cross-reactions for $\mathrm{A}_{4}, \mathrm{PREG}, \mathrm{P}_{4}$, and testosterone were $<0.01 \%$ ). The measurements were performed in duplicate. The samples $(0.2 \mathrm{ml})$ were extracted twice with $2.5 \mathrm{ml}$ toluene. To ensure redissolution of the extracted estrogens in an aqueous medium after evaporation of the organic solvent, $80 \mu \mathrm{l} 0.1 \mathrm{M} \mathrm{NaOH}$ with $0.1 \%$ BSA were added to the glass vials with the dried extracts, which were then allowed to stand for $10 \mathrm{~min}$ at $37^{\circ} \mathrm{C}$. By adding $10 \mu \mathrm{l} \mathrm{M} \mathrm{HCl}$ and $0.12 \mathrm{ml}$ concentrated phosphate buffer (2.686 g $\mathrm{KH}_{2} \mathrm{PO}_{4} ; 8.356 \mathrm{~g}$ $\mathrm{Na}_{2} \mathrm{HPO}_{4}$; and $0.325 \mathrm{~g} \mathrm{NaN}_{3}$ ad $200 \mathrm{ml} \mathrm{H}$ and an adjustment to RIA conditions were achieved (Hoffmann et al. 1996). The mean interassay coefficient of variation (CV) was $12.4 \%$ at a relative binding $\left(\mathrm{B} / \mathrm{B}_{0}\right)$ of $50 \%$. The lower limit of sensitivity was $8 \mathrm{pg} / \mathrm{ml}$.

To monitor adrenal activity during the periods of frequent blood sampling, cortisol concentrations were determined using an inhouse radioimmunological method as previously described (Hoffmann et al. 1994) after extraction of the samples with ethyl acetate. The antiserum was directed against 4-pregnene-11 $\beta, 17 \alpha, 21$-triol-3,20-dione-3-( $O$-carboxymethyl) oxime-BSA. The cross-reactions for $\mathrm{A}_{4}, \mathrm{E}_{2}$, DHEA, PREG, $\mathrm{P}_{4}$, and testosterone were $<0.01 \%$, with intraassay $C V$ and interassay CV being 7.9 and $11.6 \%$ respectively.

\section{Statistical analysis}

To cope with the right-skewed distribution of hormone data, they were transformed logarithmically to obtain an approximated normal distribution before statistical evaluation. For the individual unstimulated boars (UB1-6) and the stimulated boars sampled according to protocol 1 (SB1-3) and protocol 2 (SB4-7), pairwise cross-correlation analyses were performed to test for a correlation between the secretory profiles of steroids measured (calculation of the cross-correlation coefficient $r$ and the tail probability $P$, program BMDP6D, BMDP Statistical Software, Inc., Cork, Ireland). In addition, to test for phase shiftings, the secretory profiles were pairwise shifted relative to one another at $20 \mathrm{~min}$ intervals in both directions (from -80 to $+80 \mathrm{~min}$ ) within the cross-correlation analysis (calculation of biserial correlation function, BMDP6D, BMDP Statistical Software, Inc.). A distinct maximum of $r$ following shifting to either side would indicate that secretion of one of the steroids determined is ahead of the other one. For this type of analysis in unstimulated boars (UB1-6), pooled data over the complete sampling period were used. In stimulated boars (SB1-7), pooled data from samples after hCG application were analyzed.

\section{Results}

\section{Secretion patterns of free and sulfated steroids in unstimulated boars (UB1-6)}

Concentrations exhibited a high variability between individual animals with statistical distributions skewed to the right at each time of observation (Fig. 2). Highest concentrations were determined for DHEAS and $E_{1} S$, ranging from 2.27 to 157.6 (median, 30.1) $\mathrm{ng} / \mathrm{ml}$ and from 0.30 to 45.2 (median, 5.1) $\mathrm{ng} / \mathrm{ml}$ respectively. The concentrations measured varied between 0.12 and 9.24 (median, 1.21) ng/ml for PREGS, 0.21 and 22.6 (median, 2.29) for testosterone, 0.21 and 3.19 (median, 0.68) ng/ $\mathrm{ml}$ for $\mathrm{A}_{4}$, and 0.030 and 0.525 (median, 0.080 ) $\mathrm{ng} / \mathrm{ml}$ for $E_{1}$. The concentrations of testosterone and DHEAS showed a pronounced decrease during the sampling period, followed by a weak increase at its end. A trend to a similar secretion pattern was also observed for $E_{1} S$
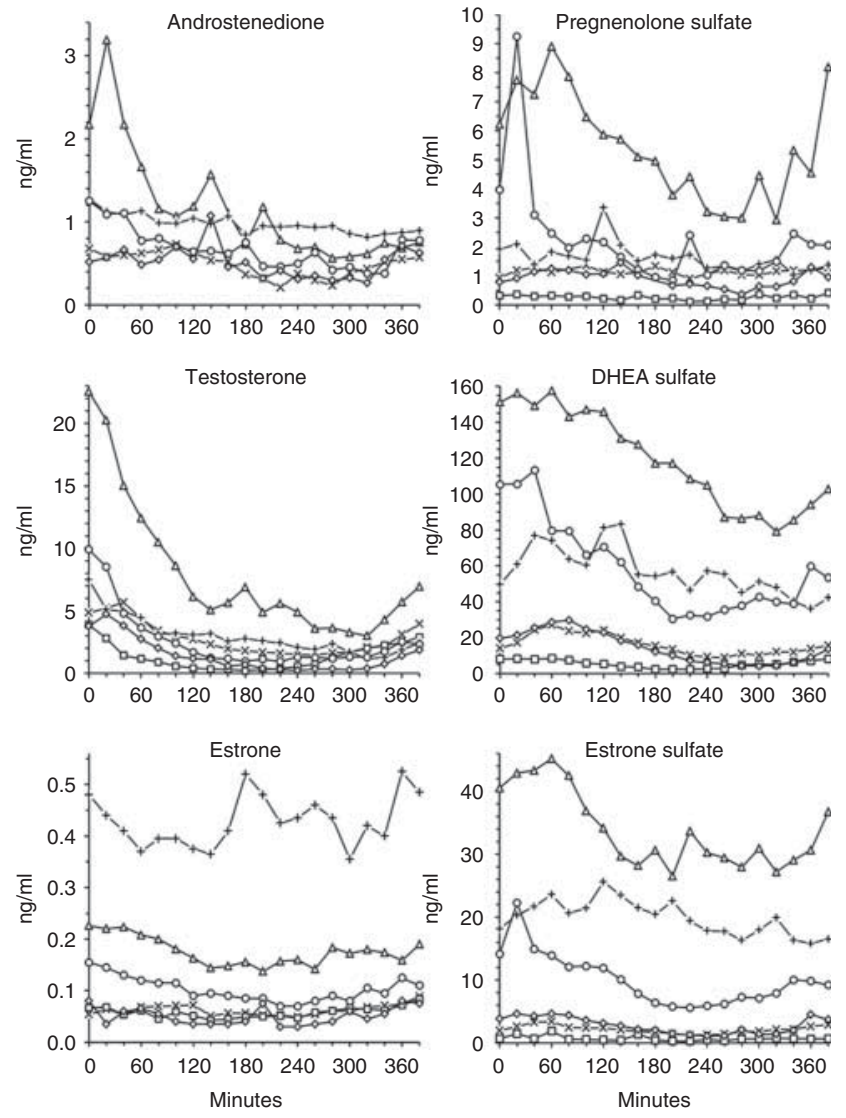

Figure 2 Concentrations of free and sulfated steroids in six postpubertal 8-11-month-old boars. Blood sampling was at $20 \mathrm{~min}$ intervals and started between 0900 and $0945 \mathrm{~h}$. In the different hormone profiles individual animals are indicated by the same symbols. 
(five of six animals, 5/6), $\mathrm{A}_{4}(3 / 5)$ as well as for $\mathrm{E}_{1}$ and PREGS (3/6).

The results of the pairwise cross-correlation analyses for correlations between the steroid profiles measured in individual animals are given in Table 1. Statistically significant correlations and high cross-correlation coefficients $(r)$ indicating similar secretion patterns were obtained for all pairs of steroids tested, but not in all animals. In all animals, the level of significance $(P<0.05)$ was reached for the following correlations: $\mathrm{A}_{4} /$ testosterone, DHEAS/A $\mathrm{A}_{4}$, DHEAS/testosterone, $\mathrm{E}_{1} \mathrm{~S} /$ PREGS, and $E_{1} S / D H E A S$. For the remaining correlations, the level of significance was not reached in up to three animals. In each case $r$ was positive.

\section{Secretion patterns of free and sulfated steroids in hCG-stimulated boars (SB1-7, protocols 1 and 2)}

For all steroids measured, the prestimulatory levels and particularly the profile after hCG application exhibited a high variability between animals also showed distributions skewed to the right (Fig. 3). Application of 1500 IU hCG had a stimulatory effect on all steroids assessed, but not in all boars. The highest relative stimulatory effect - calculated as the maximum poststimulatory concentration determined relative to the mean of the prestimulatory values - was observed for PREGS (median, 518\%; range, 256-1210\%), followed by testosterone (458\%; 317-1823\%), DHEAS (382\%; $247-1245 \%), \mathrm{A}_{4}(256 \% ; 115-773 \%), \mathrm{E}_{1} \mathrm{~S}(244 \%, 157-$ $613 \%)$, and $\mathrm{E}_{1}(158 \% ; 133-326 \%)$. In animals sampled according to protocol 2, arithmetic mean $(\bar{X})$ and S.D. were calculated from the four prestimulatory samples, and a stimulatory effect of hCG application was defined as the occurrence of concentrations higher than $\bar{X}+3$ S.D. for at least $1 \mathrm{~h}$ during the poststimulatory period. According to this definition, a poststimulatory increase in PREGS, DHEAS, $E_{1} S$, and testosterone was observed in all four boars and in $A_{4}$ and $E_{1}$ in three animals. In animals with a detectable increase, the concentrations exceeding the threshold level set $(\bar{X}+3$ s.D.) were reached between 30 and 80 (median, 30) min for PREGS, between 30 and 50 (30) min for DHEAS, and between 30 and 100 (30) min for $E_{1} S$. For $A_{4}$, testosterone, and $E_{1}$, the increase was observed between 40 and 100 (80) min, 30 and 280 (40) min, and 50 and 320 (240) min respectively.

The results of the pairwise cross-correlation analyses for correlations between the steroid profiles established for the poststimulatory period are given in Table 2 . As with unstimulated boars, statistically significant positive correlations and high cross-correlation coefficients $(r)$ were obtained for all pairs of steroids tested, but not in all animals. In all animals, significant positive correlations were obtained for the following steroid pairs: $\mathrm{A}_{4} /$ testosterone, PREGS/A ${ }_{4}$, PREGS/testosterone, DHEAS/testosterone, $E_{1} S /$ testosterone, DHEAS/PREGS,

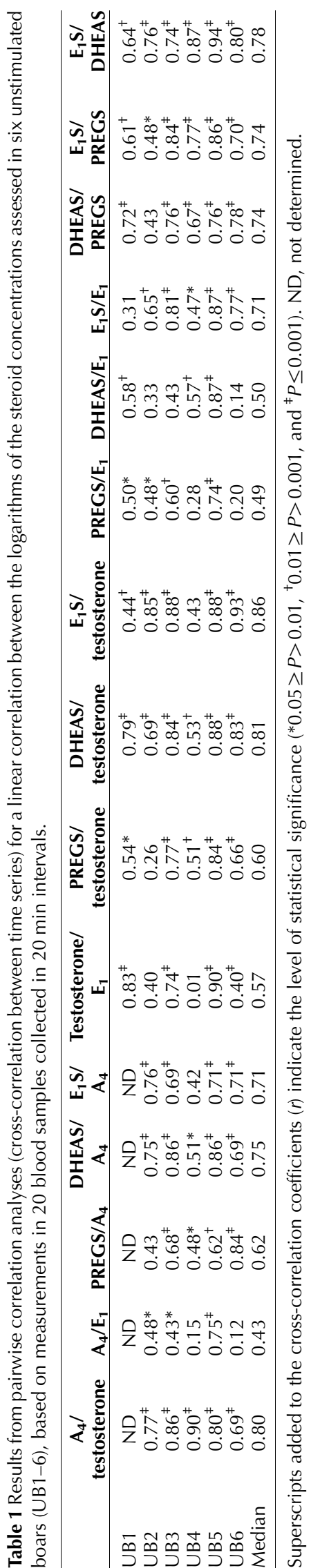

Reproduction (2014) 148 303-314 

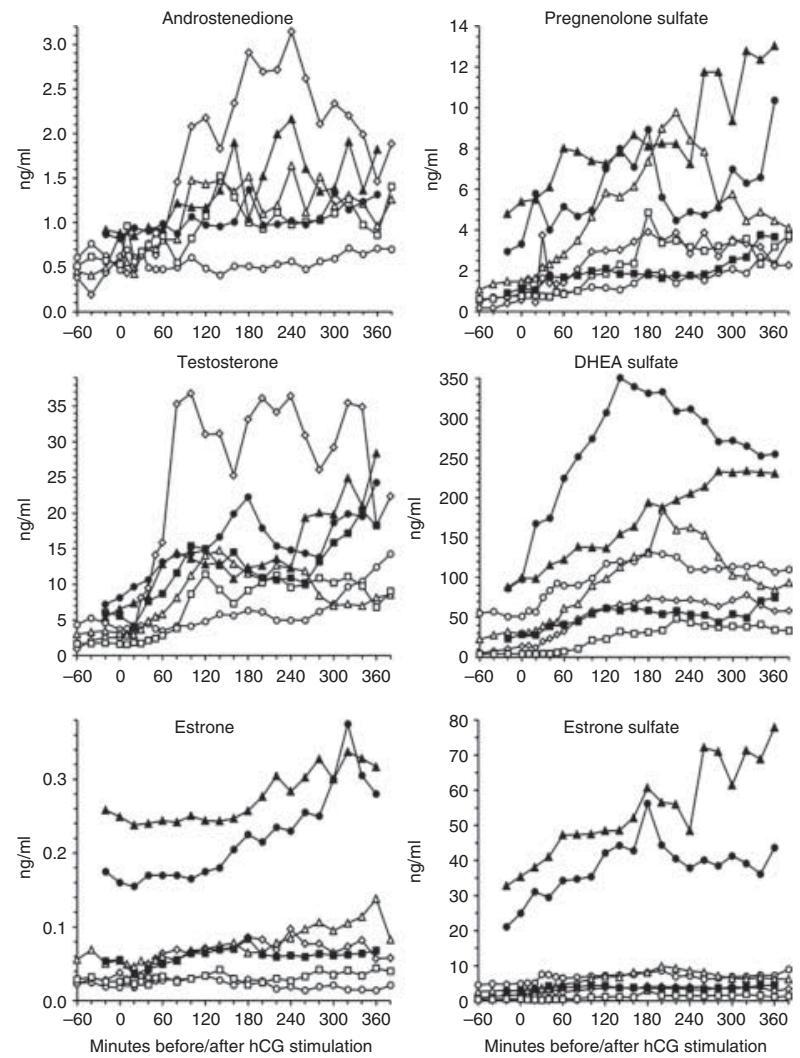

Figure 3 Concentrations of free and sulfated steroids in postpubertal 9-15-month-old boars before and after hCG application (1500 IU). In three animals, hCG was administered after two prestimulatory samples and sample collection was continued at 20 min intervals (protocol 1, closed symbols). In another four animals, four prestimulatory samples were taken and the sampling intervals were reduced to 10 min during the first hour after hCG application (protocol 2, open symbols). Blood sampling was started between 0900 and $0945 \mathrm{~h}$. In the different hormone profiles individual animals are indicated by the same symbols.

$E_{1} S / P R E G S$, and $E_{1} S / D H E A S$. For the pair $E_{1} S / E_{1}$, a significantly positive correlation occurred only in three of seven animals. For the remaining steroid pairs, significantly positive correlations were obtained in four to six animals. However, other than in unstimulated animals, in one stimulated boar (SB4) the correlation analyses yielded partially negative correlations, which were statistically significant for $\mathrm{A}_{4} / \mathrm{E}_{1} \quad(r=-0.417$, $P=0.048)$ and testosterone/ $\mathrm{E}_{1}(r=-0.444, P=0.034)$.

\section{Observations from biserial correlation functions}

Supplementary Figs 1 and 2, see section on supplementary data given at the end of this article show the results of the calculation of biserial correlation functions using pooled data from unstimulated and hCGstimulated boars. When analyzing data from unstimulated boars, a pairwise shift of the steroid profiles relative to one another led to a recognizable decrease in $r$ in either direction for the pairs $A_{4} /$ testosterone and PREGS/A $A_{4}$, consistent with a simultaneous secretion of these steroids into the systemic circulation. For the pairs $A_{4} / E_{1}$, testosterone/ $\mathrm{E}_{1}$, DHEAS/testosterone, and DHEAS/ $\mathrm{E}_{1}$, $r$ increased noticeably when the profiles were shifted relative to one another in one of the two directions. The direction of the shifting leading to an increase in $r$ indicates that secretion of $E_{1}$ precedes the secretion of $\mathrm{A}_{4}$ and testosterone, while testosterone and $\mathrm{E}_{1}$ precede the secretion of DHEAS. For the remaining pairs of steroids tested, only minor changes in $r$ were observed.

Stimulation with hCG abolished the above-mentioned evidence for phase shiftings, with the exception of the pair DHEAS/ $\mathrm{E}_{1}$, where the biserial correlation function still indicates that secretion of $E_{1}$ precedes the secretion of DHEAS. Moreover, the results obtained in stimulated boars for the pair $E_{1} S / D H E A S$ are consistent with the secretion of $E_{1} S$ preceding that of DHEAS. However, with the exception of the pairs PREGS/E $E_{1}$ and $E_{1} S / E_{1}$, where $r$ remained on a similar level over the range of phase shiftings tested, for the remaining pairs of steroids the results clearly point to a simultaneous secretion into the systemic circulation.

\section{Concentrations of free and sulfated steroids measured in a boar stimulated with an increased dosage of hCG and sampled at shorter intervals (protocol 3)}

Although the dosage of hCG (10000 IU) was significantly higher than that in protocols 1 and 2 (1500 IU), the stimulatory effect was not noticeably different (Fig. 4). The maximum relative stimulatory effects in comparison with the mean prestimulatory level varied between $122 \%$ for $E_{1}$ and $481 \%$ for testosterone. The limit of $\bar{X}+3$ S.D. of prestimulatory concentrations was first exceeded at $15 \mathrm{~min}$ for testosterone, PREGS, $\mathrm{E}_{1} \mathrm{~S}$, and $\mathrm{E}_{2} \mathrm{~S}$, followed by $\mathrm{E}_{2}(24 \mathrm{~min})$, DHEAS (30 min), $\mathrm{A}_{4}$ (42 $\mathrm{min})$, and $\mathrm{E}_{1}$ (48 min).

\section{Concentrations of free and sulfated steroids in afferent and efferent blood vessels of the testis}

Four animals were included in this part of the study. As with peripheral profiles, the absolute concentrations in local blood vessels of the testicular-epididymal compartment showed a high variability between animals. However, the relative concentrations between the various blood vessels were rather similar (Fig. 5). The concentrations in the efferent blood vessels (capsular veins and testicular vein; Fig. 1) were clearly higher compared with the afferent blood vessels (testicular artery and capsular artery) and the peripheral circulation (auricular vein), and for all steroids assessed there was a tendency to higher concentrations in the capsular veins compared with the testicular vein. No substantial difference was found between steroid concentrations measured in the testicular artery and the capsular artery, which were similar to the levels observed in the auricular vein. 


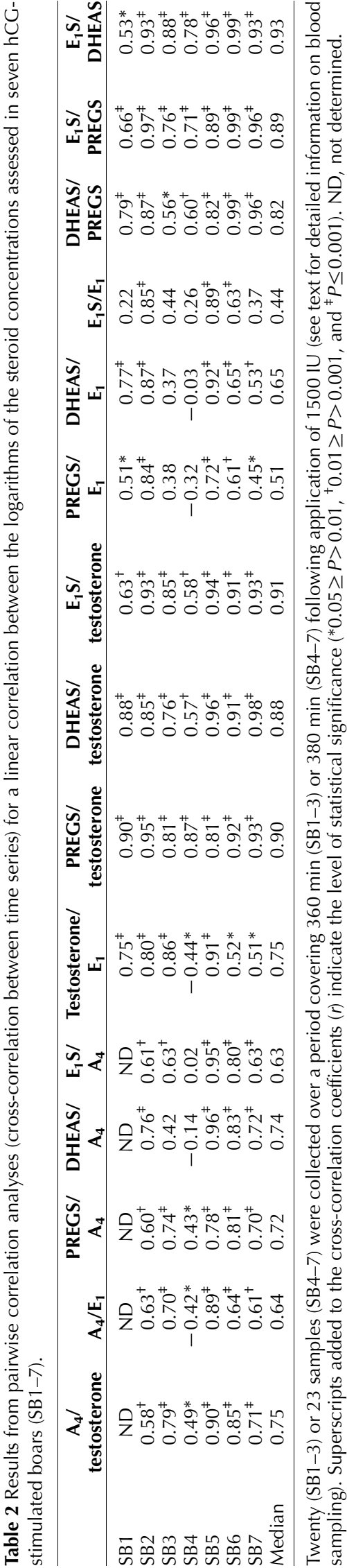

\section{Observations on the secretion of $E_{2} S$ and $E_{2}$}

As indicated earlier, the method for the determination of $\mathrm{E}_{2} \mathrm{~S}$ became available late in the ongoing study. The assay of $E_{2} S$ and $E_{2}$ was therefore restricted to the samples collected from local blood vessels and samples collected from two stimulated boars (SB6, protocol 2; Fig. 6 and SB8, protocol 3; Fig. 4). The prestimulatory concentrations of $\mathrm{E}_{2} \mathrm{~S}$ were in the lower $\mathrm{ng} / \mathrm{ml}$ range (SB6, $0.8 \pm$ 0.1 and SB8, 6.9 \pm 0.2 ) and were lower compared with $\mathrm{E}_{1} \mathrm{~S}$ (ratio $\mathrm{E}_{1} \mathrm{~S} / \mathrm{E}_{2} \mathrm{~S}, 3.5$ and 2.6). $\mathrm{E}_{2} \mathrm{~S}$ was clearly stimulated by both dosages of hCG, with the maximum relative stimulatory effect being 494\% in SB6 (1500 IU hCG) and 221\% in SB8 (10 000 IU hCG). The prestimulatory concentrations of $E_{2}$ were $40.0 \pm 2.5 \mathrm{pg} / \mathrm{ml}$ (SB6) and $290.0 \pm 12.2 \mathrm{pg} / \mathrm{ml}$ (SB8), with the ratios of $E_{1} / E_{2}$ being 0.6 and 1.4 respectively. The maximum relative stimulatory effect of hCG was 255\% in SB6 and 223\% in SB8. In both animals, high correlation coefficients were found for $E_{2} / E_{1}\left(S B 6,0.90\right.$ and SB8, 0.86), $E_{1} S / E_{2}$ (0.73 and 0.89), $E_{2} S / E_{2}(0.75$ and 0.86$)$, and $E_{1} S / E_{2} S$ (0.99 and 0.96). Measurements of $E_{2}$ and $E_{2} S$ concentrations in local blood vessels and peripheral blood yielded similar relative concentrations as obtained for other steroids (Fig. 5).

\section{Discussion}

Newly developed LC-MS/MS methods were used for the measurement of PREGS, DHEAS, $\mathrm{E}_{1} \mathrm{~S}$, and $\mathrm{E}_{2} \mathrm{~S}$ in blood plasma. Also testosterone and $A_{4}$ were determined by LC-MS/MS, which allows the analysis of free and intact sulfated steroids with currently the highest specificity and good sensitivity and without the need for chemical modification of the analyte (Galuska et al. 2013). Only $E_{1}$ and $E_{2}$ were determined by highly sensitive RIAs, due to the expected low concentrations of these steroids (Claus \& Hoffmann 1980, Schwarzenberger et al. 1993). Owing to high specificity of the antisera used for the measurement of free estrogens, a substantial impairment of the results by cross-reactions with other steroids is very unlikely. By applying these methods, it was possible for the first time to establish the profiles of free and sulfated steroids in boars by frequent sampling over a longer period of time in order to test for correlations in secretory patterns and shifts in secretion and to come to possible conclusions on the different sources of origin or transport. By collecting blood from different sites in the testicular-epididymal compartment, the data obtained should further allow conclusions on the existence of a sulfatase pathway in the porcine testicular-epididymal compartment. The key elements of such a pathway have already been described, such as the production of high amounts of sulfated estrogens (Claus \& Hoffmann 1980, Schwarzenberger et al. 1993, Zamaratskaia et al. 2004, Hoffmann et al. 2010), considerable expression and activity of steroid sulfatase in porcine Leydig cells and 


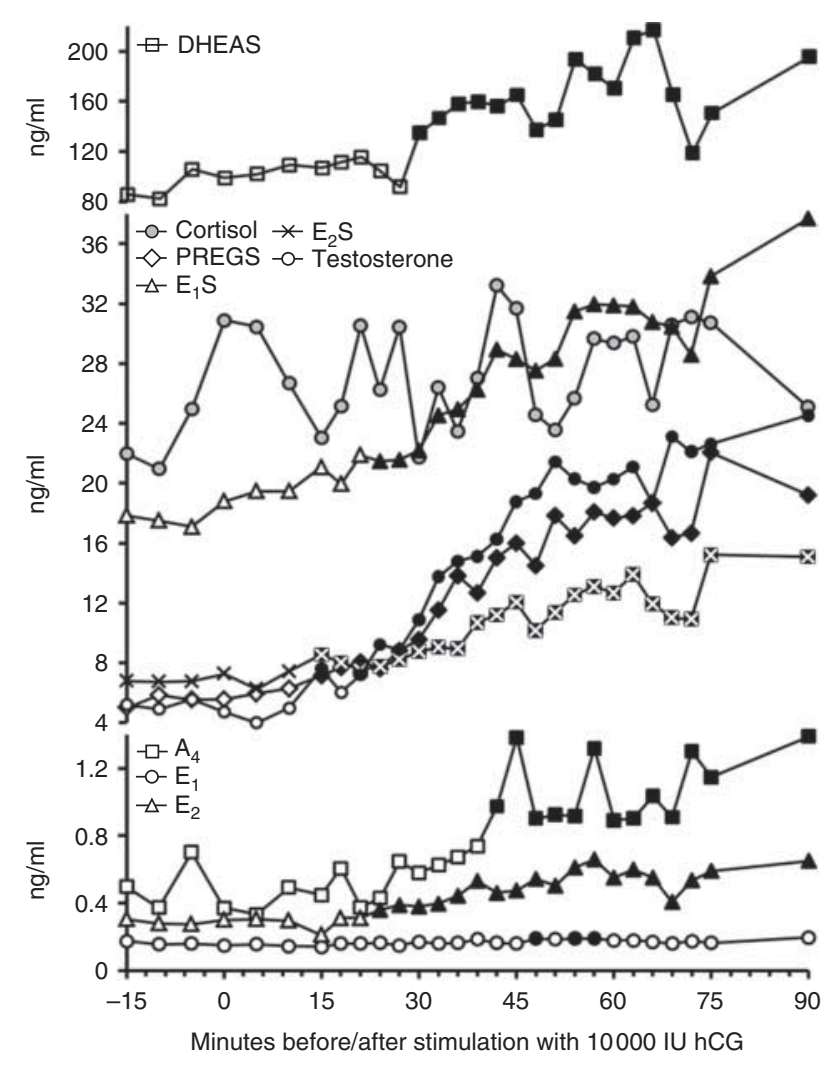

Figure 4 Concentrations of androstenedione $\left(A_{4}\right)$, estrone $\left(E_{1}\right)$, estradiol-17 $\beta\left(\mathrm{E}_{2}\right)$, testosterone, pregnenolone sulfate (PREGS), DHEA sulfate (DHEAS), estrone sulfate $\left(E_{1} S\right)$, and estradiol-17 $\beta$-3-sulfate $\left(E_{2} S\right)$ in an 11.5-month-old boar (SB8) before and after stimulation with $10000 \mathrm{IU}$ hCG. Sampling was in 5 min intervals from $15 \mathrm{~min}$ before until $15 \mathrm{~min}$ after hCG application, followed by sampling at $3 \mathrm{~min}$ intervals (protocol 3). Solid symbols indicate concentrations exceeding arithmetic mean plus threefold S.D. calculated from the four prestimulatory samples. In this animal, cortisol was also measured by RIA to monitor adrenal activity during the sampling period.

epididymis, and substantial estrogen sulfotransferase activity in the epididymis (Mutembei et al. 2009, Hoffmann et al. 2010, Zdunczyk et al. 2012). Moreover, various cell types of the porcine testis and epididymis exhibit a high expression of estrogen receptors (Mutembei et al. 2005, Pearl et al. 2007). Consequently, sulfated estrogens may serve as substrates for local sulfatase pathways in the porcine testicular-epididymal compartment.

Despite high individual variability, the results obtained in unstimulated animals suggest that in principle secretion of all steroids measured follows a similar pattern. High positive correlations were especially found between the profiles for testosterone, PREGS, DHEAS, and $\mathrm{E}_{1} \mathrm{~S}$, for which in a considerable number of cases, a more or less pronounced gradual decline in concentrations was observed during the sampling period, followed by a weak increase at its end. This pattern is consistent with previously published diurnal profiles for $5 \alpha$-androstenone, testosterone,
DHEAS, and total conjugated estrogens (Claus \& Hoffmann 1980, Tan \& Raeside 1980), pointing to episodic fluctuations or pulsatile secretion with a low frequency of three to five pulses per day. This pattern does not seem to be influenced appreciably by a possible stress-induced adrenal steroid secretion caused by sedation and sampling, as cortisol concentrations measured by RIA $(37.8 \pm 17.1 \mathrm{ng} / \mathrm{ml}$; range, $5.2-$ $83.6 \mathrm{ng} / \mathrm{ml}$ ) were in a similar range as previously reported for boars (Allrich et al. 1982, Bishop et al. 1999, Wise et al. 2000) and either remained virtually unchanged during the sampling period or exhibited a profile clearly different from the steroids being in the focus of this study (see Supplementary Fig. 3, see section on supplementary data given at the end of this article). The generally lower correlations of the secretion patterns of $A_{4}$ and $E_{1}$ with the other steroids may in part result from the fact that in a considerable proportion of samples with their levels in the lower measuring range, accuracy
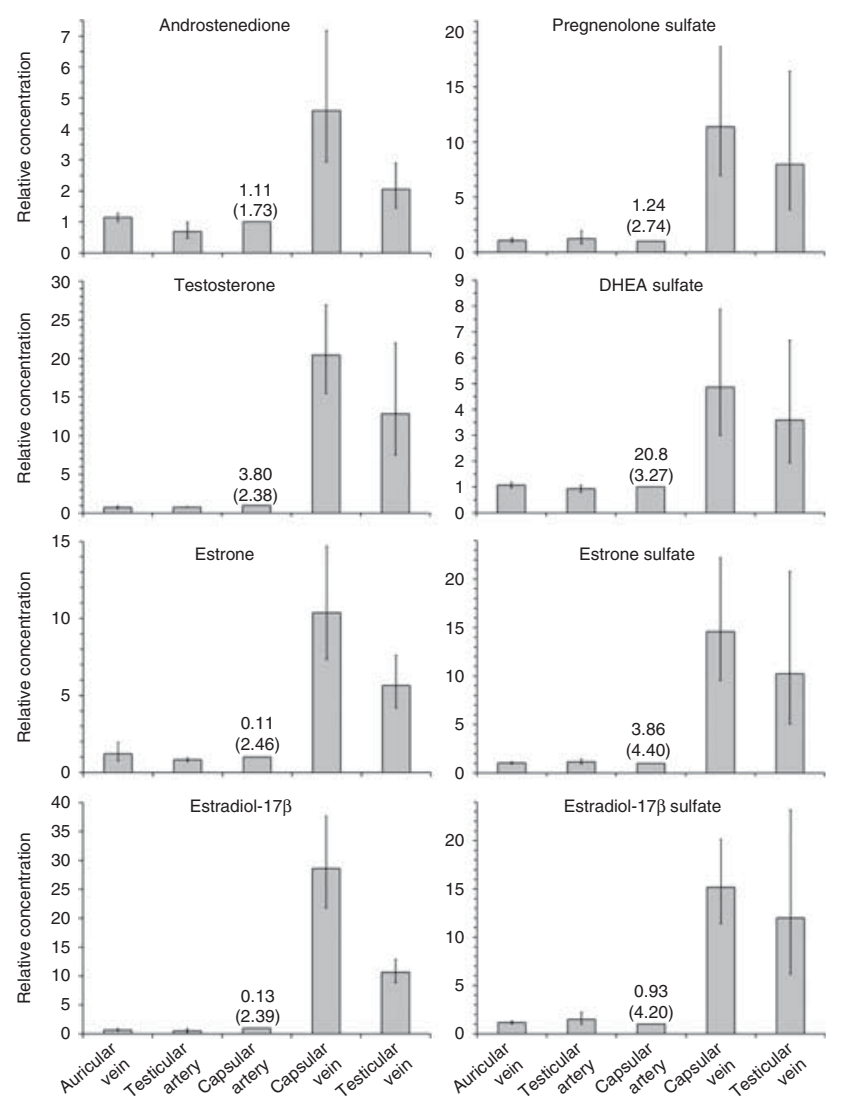

Figure 5 Concentrations of free and sulfated steroids measured in the systemic circulation (auricular vein) and in local blood vessels of the testicular-epididymal compartment of four boars (for exact localizations of sampling see Fig. 1). The results are expressed as multiples of the value measured in the terminal branch of the testicular artery running on the testicular surface ('capsular artery') and are presented as geometric mean and scatter range. The figures in the diagrams indicate the absolute concentration measured in the capsular artery $(\mathrm{ng} / \mathrm{ml})$ as geometric mean and dispersion factor (in parentheses). 


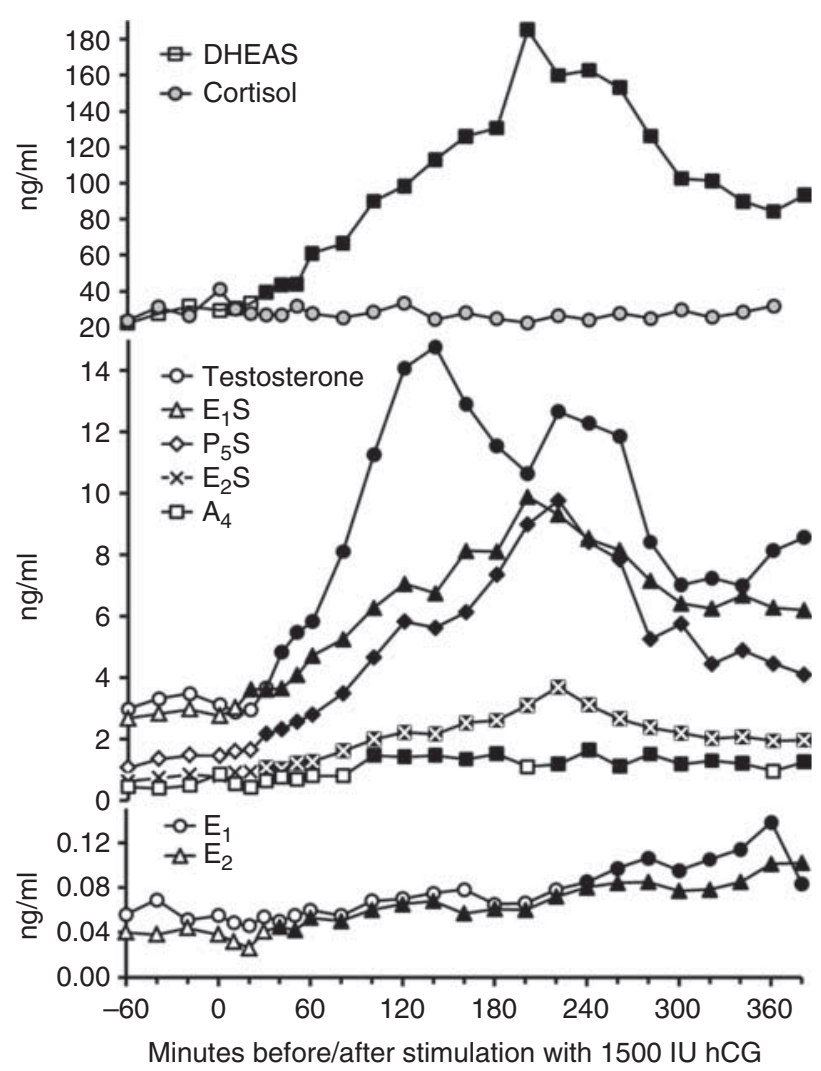

Figure 6 Profiles of free and sulfated steroids before and after hCG stimulation (1500 IU; protocol 2). Solid symbols indicate concentrations exceeding arithmetic mean plus threefold S.D. calculated from the four prestimulatory samples. In this animal (SB6), cortisol was also measured by RIA to monitor adrenal activity during the sampling period. $\mathrm{A}_{4}$, androstenedione; $\mathrm{E}_{1}$, estrone; PREGS, pregnenolone sulfate; $\mathrm{E}_{1} \mathrm{~S}$, estrone sulfate.

is inherently reduced. Nevertheless, a consistently high correlation was observed between $\mathrm{A}_{4}$ and testosterone, indicating a sufficient accuracy of $\mathrm{A}_{4}$ measurements also in animals exhibiting low concentrations.

In addition to the characterization of spontaneous steroid secretion, stimulation with 1500 IU hCG was performed to create a more dynamic situation for correlation analysis and to obtain possible evidence of differential transport as indicated by the time elapsed between hCG stimulation and detection of a stimulatory effect. The results obtained in one animal after stimulation with $10000 \mathrm{IU}$ hCG (Fig. 4) suggest that $1500 \mathrm{IU}$ were sufficient to exert maximum stimulation. As with unstimulated animals, the results obtained in stimulated boars exhibited a considerable variability between animals, concerning the prestimulatory levels, the maximum stimulatory effect, and the shape of the poststimulatory profile. However, clear evidence was obtained that basically all steroids assessed are stimulated by hCG. Moreover, data show that increases in PREGS, DHEAS, $E_{1} S$, and $E_{2} S$ became obvious within 15-40 min after hCG application, which was not later than observed for free steroids. Thus, a transport of significant amounts of free estrogens to the epididymis after entry into the tubular fluid and their sulfation by epididymal sulfotransferase are very unlikely. From their measurements in blood and lymph of the spermatic cord, Setchell et al. (1983) concluded that testosterone and free estrogens preferentially leave the testis via the blood, whereas sulfated estrogens and DHEAS are predominantly transported into the systemic circulation via the lymph. If so, our results suggest that both systems accomplish the transport into the peripheral circulation at a similar pace and with similar efficiency. As with unstimulated boars, cortisol concentrations (43.9 \pm $19.6 \mathrm{ng} / \mathrm{ml}$; range, $16.6-103.5 \mathrm{ng} / \mathrm{ml}$ ) remained fairly constant or exhibited a profile clearly different from other steroids (see Supplementary Fig. 4, see section on supplementary data given at the end of this article). Thus, also in hCG-stimulated animals, a noteworthy interference of the profiles by steroids of adrenal origin is very unlikely.

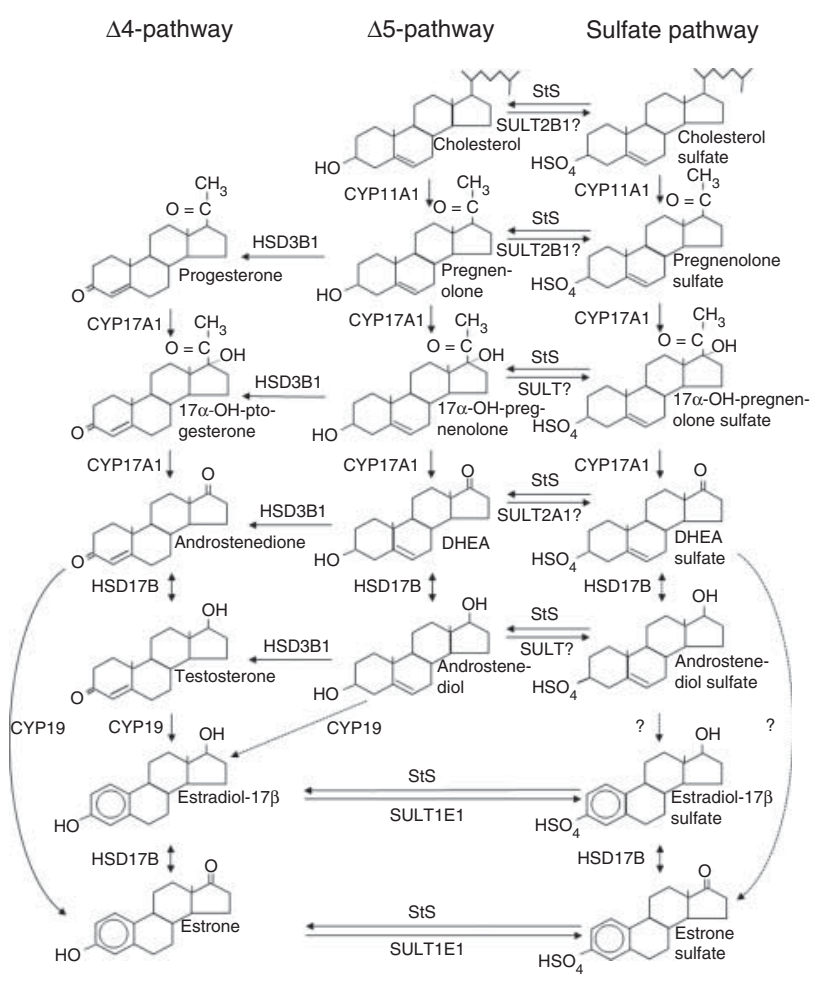

Figure 7 Hypothetical pathways for the synthesis of free and sulfated steroids in porcine Leydig cells. More speculative steps of this concept are indicated by dotted lines and question marks. CYP11A1, side chain-cleavage enzyme; CYP17A1, 17 $\alpha$-hydroxylase-C17,20-lyase; HSD3B1, $3 \beta$-hydroxysteroid dehydrogenase- $\Delta 5 / 4$-isomerase; CYP19, aromatase; SULT, cytosolic sulfotransferase; StS, steroid sulfatase. Steroidal pheromones (16-androstene steroids) diverge from pregnenolone or pregnenolone sulfate under the andien- $\beta$-synthase activity of CYP17A1 in the presence of adequate levels of cytochrome b5 (Meadus et al. 1993, Sinclair et al. 2005). 
In order to obtain evidence for differential distribution between the individual steroids, biserial correlation functions were calculated to test pairwise for time shifts between their profiles. Biserial correlation functions for the pairs $\mathrm{A}_{4} / \mathrm{E}_{1}$, testosterone/ $\mathrm{E}_{1}$, DHEAS/testosterone, and DHEAS/ $E_{1}$ in unstimulated boars and for the pairs DHEAS $/ \mathrm{E}_{1}$ and DHEAS/ $\mathrm{E}_{1} \mathrm{~S}$ in stimulated boars showed their maxima outside of the point of origin when the respective profiles were shifted relative to one another. However, this effect was only moderate and generally inconsistent between stimulated and unstimulated boars. Thus, these observations cannot be regarded as reliable indications of time shifts. One could argue that the sampling interval of 20 min was too long to detect relevant time shifts. However, no evidence for a phase shift between free and sulfated steroids was obtained in a pilot experiment when the sampling interval in the poststimulatory period was reduced to $3 \mathrm{~min}$ (Fig. 4). This further corroborates the concept that the production of sulfated steroids is immediately linked to the production of testosterone in porcine Leydig cells. Further evidence for the predominant production of sulfated steroids in testicular tissue comes from the measurements in local blood vessels. In the four animals assessed, the levels of all steroids measured were clearly higher in capsular veins compared with the capsular artery, whereas the levels in the capsular artery were virtually identical to the concentrations in the proximal part of the testicular artery and to systemic blood. These results are clearly in contrast to the concept that the pampiniform plexus and testicular artery not only form a counter-current exchanger for heat but also for hormones (Rerkamnuaychoke et al. 1991, Einer-Jensen \& Hunter 2005) and they provide no evidence for a significant contribution of the epididymis to the levels of sulfated steroids measured in the testicular vein.

Previous studies on conjugated estrogens in boars focused mainly on $E_{1} S$ or total conjugated estrogens, specific data for $E_{2} S$ are only sparsely available (Schwarzenberger et al. 1993). Consistent with this earlier report, $E_{2} S$ concentrations were somewhat lower in comparison with $E_{1} S$ but still sizeable. The measurements in the capsular artery and veins clearly show that $\mathrm{E}_{2} \mathrm{~S}$ - as also the other steroid sulfates assessed - is predominantly an original product of the testis.

In conclusion, this study provides clear evidence that in boars all the steroids assessed are predominantly produced in testicular tissue. Moreover, the high correlations found between the secretory profiles and the similarly short periods between hCG stimulation and the detection of increases in peripheral blood suggest that they originate from an identical cellular source, yielding no evidence for a differential transport between sulfated estrogens and other free and sulfated steroids. These observations point to a role of sulfated steroids as precursors or intermediates of steroidogenesis in Leydig cells rather than as inactivated end products.
The direct production of sulfated estrogens from sulfated precursors ('sulfate pathway'; Fig. 7) would be a plausible explanation for the high testicular output of sulfated estrogens in the absence of a detectable estrogen sulfotransferase activity in the testis (Hoffmann et al. 2010). Moreover, a substantial use of sulfated precursors for the production of estrogens, androgens, or steroidal pheromones would provide an explanation for the intriguingly broad spectrum of sulfated steroids found in boars (Ruokonen \& Vihko 1974, Raeside et al. 2006) and would assign a crucial regulatory role to steroid sulfatase in porcine testicular steroidogenesis. However, a significant sulfonation of free steroids in porcine Leydig cells cannot be ruled out completely even in the presence of only weak activities of steroid-specific SULTs due to the high total mass of these cells in boars.

\section{Supplementary data}

This is linked to the online version of the paper at http://dx.doi. org/10.1530/REP-14-0193.

\section{Declaration of interest}

The authors declare that there is no conflict of interest that could be perceived as prejudicing the impartiality of the research reported.

\section{Funding}

This study was funded by the German Research Foundation (DFG), within DFG Research Group 1369 'Sulfated Steroids in Reproduction' to subproject 4 (Gerhard Schuler, principal investigator) and subproject 7 (Stefan A Wudy, principal investigator).

\section{Acknowledgements}

The authors thank Nathalia Rosero for the help with the collection of blood samples, Marion Sparenberg for support with the statistical calculations, and Carol Pallauf for linguistic revision of the manuscript.

\section{References}

Allrich RD, Christenson RK, Ford JJ \& Zimmerman DR 1982 Pubertal development of the boar: testosterone, estradiol-17 $\beta$, cortisol and LH concentrations before and after castration at various ages. Journal of Animal Science 55 1139-1146.

At-Taras EE, Kim IC, Berger T, Conley A \& Roser JF 2008 Reducing endogenous estrogen during development alters hormone production by porcine Leydig cells and seminiferous tubules. Domestic Animal Endocrinology 34 100-108. (doi:10.1016/j.domaniend.2006.11.003)

Back DJ, Breckenridge AM, Crawford FE, Giles M, Orme ML \& Rowe PH 1981 The pharmacokinetics of oestrone sulphate in the rat. Journal of Steroid Biochemistry 14 1045-1047. (doi:10.1016/00224731(81)90214-4)

Baulieu EE, Fabre-Jung I \& Huis in't Veld LG 1967 Dehydroepiandrosterone sulfate: a secretory product of the boar testis. Endocrinology 81 34-38. (doi:10.1210/endo-81-1-34) 
Bishop JD, Malven PV, Singleton WL \& Weesner GD 1999 Hormonal and behavioral correlates of emotional states in sexually trained boars. Journal of Animal Science 77 3339-3345.

Bortfeld M, Rius M, König J, Herold-Mende C, Nies AT \& Keppler D 2006 Human multidrug resistance protein 8 (MRP8/ABCC11), an apical efflux pump for steroid sulfates, is an axonal protein of the CNS and peripheral nervous system. Neuroscience 137 1247-1257. (doi:10.1016/j.neuroscience.2005.10.025)

Claus R \& Hoffmann B 1980 Oestrogens compared to other steroids of testicular origin, in blood plasma of boars. Acta Endocrinologica $\mathbf{9 4}$ 404-411.

Conley AJ, Corbin CJ, Hinshelwood MM, Liu Z, Simpson ER, Ford JJ \& Harada N 1996 Functional aromatase expression in porcine adrenal gland and testis. Biology of Reproduction 54 497-505. (doi:10.1095/ biolreprod54.2.497)

Duanmu Z, Weckle A, Koukouritaki SB, Hines RN, Falany JL, Falany CN, Kocarek TA \& Runge-Morris M 2006 Developmental expression of aryl, estrogen, and hydroxysteroid sulfotransferases in pre- and postnatal human liver. Journal of Pharmacology and Experimental Therapeutics 316 1310-1317. (doi:10.1124/jpet.105.093633)

Einer-Jensen N \& Hunter R 2005 Counter-current transfer in reproductive biology. Reproduction 129 9-18. (doi:10.1530/rep.1.00278)

Fraczek B, Kotula-Balak M, Wojtusiak A, Pierściński A \& Bilińska B 2001 Cytochrome $\mathrm{P} 450$ aromatase in the testis of immature and mature pigs. Reproductive Biology 1 51-59.

Galuska CE, Hartmann MF, Sánchez-Guijo A, Bakhaus K, Geyer J, Schuler G, Zimmer KP \& Wudy SA 2013 Profiling intact steroid sulfates and unconjugated steroids in biological fluids by liquid chromatography-tandem mass spectrometry (LC-MS-MS). Analyst 138 3792-3801. (doi:10.1039/c3an36817c)

Geyer J, Godoy JR \& Petzinger E 2004 Identification of a sodium-dependent organic anion transporter from rat adrenal gland. Biochemical and Biophysical Research Communications 316 300-306. (doi:10.1016/ j.bbrc.2004.02.048)

Hähnel R, Twaddle E \& Ratajcza T 1973 Specificity of estrogen receptor of human uterus. Journal of Steroid Biochemistry 4 21-31. (doi:10.1016/ 0022-4731(73)90076-9)

Hoffmann B, Höveler R, Hasan SH \& Failing K 1992 Ovarian and pituitary function in dogs after hysterectomy. Journal of Reproduction and Fertility 96 837-845. (doi:10.1530/jrf.0.0960837)

Hoffmann B, Höveler R, Nohr B \& Hasan SH 1994 Investigations on hormonal changes around parturition in the dog and the occurrence of pregnancy-specific non conjugated oestrogens. Experimental and Clinical Endocrinology 102 185-189. (doi:10.1055/s-00291211280)

Hoffmann B, Gentz F \& Failing K 1996 Investigations into the course of progesterone-, oestrogen- and eCG-concentrations during normal and impaired pregnancy in the mare. Reproduction in Domestic Animals 32 717-723. (doi:10.1111/j.1439-0531.1996.tb01444.x)

Hoffmann B, Rostalski A, Mutembei HM \& Goericke-Pesch S 2010 Testicular steroid hormone secretion in the boar and expression of testicular and epididymal steroid sulphatase and estrogen sulphotransferase activity. Experimental and Clinical Endocrinology \& Diabetes 118 274-280. (doi:10.1055/s-0029-1231082)

Kuiper GG, Carlsson B, Grandien K, Enmark E, Häggblad J, Nilsson S \& Gustafsson JA 1997 Comparison of the ligand binding specificity and transcript tissue distribution of estrogen receptors $\alpha$ and $\beta$. Endocrinology 138 863-870.

Meadus WJ, Mason JI \& Squires EJ 1993 Cytochrome P450c17 from porcine and bovine adrenal catalyses the formation of 5,16-androstadien-3 $\beta$-ol from pregnenolone in the presence of cytochrome b5 Journal of Steroid Biochemistry and Molecular Biology 46 565-572. (doi:10.1016/0960-0760(93)90183-W)

Mendel CM 1989 The free hormone hypothesis: a physiologically based mathematical model. Endocrine Reviews 10 232-274. (doi:10.1210/ edrv-10-3-232)

Meyers SA, Lozon MM, Corombos JD, Saunders DE, Hunter K, Christensen C \& Brooks SC 1983 Induction of porcine uterine estrogen sulfotransferase activity by progesterone. Biology of Reproduction $\mathbf{2 8}$ 1119-1128. (doi:10.1095/biolreprod28.5.1119)
Mutembei HM, Pesch S, Schuler G \& Hoffmann B 2005 Expression of oestrogen receptors $\alpha$ and $\beta$ and of aromatase in the testis of immature and mature boars. Reproduction in Domestic Animals 40 228-236. (doi:10.1111/j.1439-0531.2005.00586.x)

Mutembei HM, Kowalewski MP, Ugele B, Schuler G \& Hoffmann B 2009 Expression and activity of steroid sulphatase in the boar testis. Reproduction in Domestic Animals 44 17-23. (doi:10.1111/j.14390531.2007.00983.x)

Niiyama M, Yonemichi H, Harada E, Syuto B \& Kitagawa A 1985 A simple catheterization from the ear vein into the jugular vein for sequential blood sampling from unrestrained pigs. Japanese Journal of Veterinary Research 33 1-9.

Pearl CA, Berger T \& Roser JF 2007 Estrogen and androgen receptor expression in relation to steroid concentrations in the adult boar epididymis. Domestic Animal Endocrinology 33 451-459. (doi:10.1016/ j.domaniend.2006.09.003)

Raeside JI, Christie HL, Renaud RL \& Sinclair PA 2006 The boar testis: the most versatile steroid producing organ known. Society of Reproduction and Fertility 62 85-97.

Raftogianis R, Creveling C, Weinshilboum R \& Weisz J 2000 Estrogen metabolism by conjugation. Journal of the National Cancer Institute. Monographs 27 113-124.

Rago V, Aquila S, Panza R \& Carpino A 2007 Cytochrome P450arom, androgen and estrogen receptors in pig sperm. Reproductive Biology and Endocrinology 5 23. (doi:10.1186/1477-7827-5-23)

Reed MJ, Purohit A, Woo LW, Newman SP \& Potter BV 2005 Steroid sulfatase: molecular biology, regulation, and inhibition. Endocrine Reviews 26 171-202. (doi:10.1210/er.2004-0003)

Rerkamnuaychoke W, Nishida T, Kurohmaru M \& Hayashi Y 1991 Morphological studies on the vascular architecture in the boar spermatic cord. Journal of Veterinary Medical Science 53 233-239. (doi:10.1292/ jvms.53.233)

Ruokonen A \& Vihko R 1974 Steroid metabolism in testis tissue: concentrations of unconjugated and sulfated neutral steroids in boar testis. Journal of Steroid Biochemistry 5 33-38. (doi:10.1016/00224731(74)90025-9)

Santner SJ, Feil PD \& Santen RJ 1984 In situ estrogen production via the estrone sulfatase pathway in breast tumors: relative importance versus the aromatase pathway. Journal of Clinical Endocrinology and Metabolism 59 29-33. (doi:10.1210/jcem-59-1-29)

Schwarzenberger F, Toole GS, Christie HL \& Raeside JI 1993 Plasma levels of several androgens and estrogens from birth to puberty in male domestic pigs. Acta Endocrinologica 128 173-177.

Setchell BP, Laurie MS, Flint AP \& Heap RB 1983 Transport of free and conjugated steroids from the boar testis in lymph, venous blood and rete testis fluid. Journal of Endocrinology 96 127-136. (doi:10.1677/joe.0. 0960127)

Sinclair PA, Squires EJ, Raeside JI \& Renaud R 2005 Synthesis of free and sulphoconjugated 16-androstene steroids by the Leydig cells of the mature domestic boar. Journal of Steroid Biochemistry and Molecular Biology 96 217-228. (doi:10.1016/j.jsbmb.2005.02.017)

Strecker H, Hachmann H \& Seidel L 1979 Der Radioimmunotest (RIA), eine hochspezifische, extrem empfindliche quantitative Analysenmethode. Chemiker Zeitung 103 53-68.

Strott CA 1996 Steroid sulfotransferases. Endocrine Reviews 17 670-697. (doi:10.1210/edrv-17-6-670)

Tan HS \& Raeside JI 1980 Developmental patterns of plasma dehydroepiandrosterone sulfate and testosterone in male pigs. Animal Reproduction Science 3 73-81. (doi:10.1016/0378-4320(80)90032-9)

Ugele B, Bahn A \& Rex-Haffner M 2008 Functional differences in steroid sulfate uptake of organic anion transporter 4 (OAT4) and organic anion transporting polypeptide 2B1 (OATP2B1) in human placenta. Journal of Steroid Biochemistry and Molecular Biology 111 1-6. (doi:10.1016/ j.jsbmb.2008.04.001)

Weng Q, Medan MS, Watanabe G, Tsubota T, Tanioka Y \& Taya K 2005 Immunolocalization of steroidogenic enzymes P450scc, 33HSD, P450c17, and P450arom in Göttingen miniature pig testes. Journal of Reproduction and Development 51 299-304. (doi:10.1262/jrd.16077)

Willnow TE \& Nykjaer A 2010 Cellular uptake of steroid carrier proteins mechanisms and implications. Molecular and Cellular Endocrinology 316 93-102. (doi:10.1016/j.mce.2009.07.021) 
Wise T, Zanella EL, Lunstra DD \& Ford JJ 2000 Relationships of gonadotropins, testosterone, and cortisol in response to $\mathrm{GnRH}$ and GnRH antagonist in boars selected for high and low follicle-stimulating hormone levels. Journal of Animal Science 78 1577-1590.

Zamaratskaia G, Babol J, Madej A, Squires EJ \& Lundström K 2004 Agerelated variation of plasma concentrations of skatole, androstenone, testosterone, oestradiol-17 $\beta$, oestrone sulphate, dehydroepiandrosterone sulphate, triiodothyronine and IGF-1 in six entire male pigs. Reproduction in Domestic Animals 39 168-172. (doi:10.1111/j.1439-0531.2004. 00496.x)
Zduńczyk S, Janowski T, Raś A \& Barański W 2012 Activity of steroid sulphatase and estrogen sulphotransferase in the boar epididymis during the postpubertal period. Reproductive Biology 12 374-378. (doi:10. 1016/j.repbio.2012.10.012)

Received 10 April 2014

First decision 28 April 2014

Revised manuscript received 6 June 2014

Accepted 24 June 2014 